\title{
On the analogy of free will and free belief
}

\author{
Verena Wagner ${ }^{1}$
}

Received: 30 November 2014 / Accepted: 7 August 2015 / Published online: 22 August 2015

(C) The Author(s) 2015. This article is published with open access at Springerlink.com

\begin{abstract}
Compatibilist methods borrowed from the free will debate are often used to establish doxastic freedom and epistemic responsibility. Certain analogies between the formation of intention and belief make this approach especially promising. Despite being a compatibilist myself in the practical debate, I will argue that compatibilist methods fail to establish doxastic freedom. My rejection is not based on an argument against the analogy of free will and free belief. Rather, I aim at showing that compatibilist free will and free belief are equally misguided because freedom is a concept that only applies to an agent's actions and not to her mental attitudes. Compatibilist strategies that seek to define control by reason-responsiveness merely weaken the conditions for freedom such that arbitrary forms of control can be defined. I will demonstrate that these methods also commit to freedom of fear, freedom of hope and freedom of anger. However, I accept the compatibilist challenge to account for the addict's and the paranoid's unfreedom. I will sketch a unified approach to compatibilist free agency that does justice to these phenomena without the help of free will or free belief.
\end{abstract}

Keywords Doxastic freedom · Doxastic voluntarism $\cdot$ Free belief $\cdot$ Free will $\cdot$ Practical freedom - Freedom of action - Epistemic responsibility · Doxastic compatibilism . Reason-responsiveness $\cdot$ Voluntary control

Verena Wagner

v.wagner@uni-konstanz.de

1 FB Philosophie, Fach 17, Universität Konstanz, 78457 Konstanz, Germany 


\section{Introduction}

Doubts concerning the existence of a freedom that concerns an agent's doxastic life focus on dis-analogies of actions and doxastic states. While actions are usually governed by intentions and practical considerations, doxastic states are not. Actions that are governed by the agent's intentions are said to be under the agent's voluntary control and as such are apt objects for freedom. Doxastic states like beliefs are usually not controlled by the agent's intentions; therefore, it is said that they are held or formed involuntarily. This position of doxastic involuntarism was held, among others, by Williams (1973), Alston (1988) and Bennett (1990). For Williams, it is impossible to form a belief that $p$ while knowing that the evidence speaks against the truth of $p$. Since beliefs "aim at truth" and are considered by us as "something purporting to represent reality" (Williams 1973, p. 148), we cannot consciously acquire beliefs at will that we do not take to be justified. For Alston the fact that we are so constituted is merely contingent and he challenges his readers with asking whether they are able "to believe that the U. S. is still a colony of Great Britain, just by deciding to do so" (Alston 1988, p. 263). Most people will have to answer this question in the negative: we simply lack the ability to acquire this belief at will, just like that, without further help by indirect means and against the evidence that speaks for the contrary. The answer to the question as to whether we enjoy a similar freedom with regard to our doxastic states as we do with regard to our actions, seems to be clearly negative. The lack of voluntary control seems to make agents generally unfree in their doxastic attitudes. But maybe this result is premature and there is something more to say about 'doxastic freedom' meaning a form of control we have with regard to our doxastic states that goes beyond indirect doxastic control over a longer period of time.

There are two ways to respond to the doxastic involuntarist's challenge in order to uphold the idea of doxastic freedom. This can be done either by defending doxastic voluntarism on the basis that there is some different kind of voluntary control over doxastic states other than by intentions or practical considerations; or this can be done by denying that doxastic voluntarism is required for the kind of control that is needed for doxastic freedom in the first place. The first way was most prominently pursued by Sharon Ryan and Matthias Steup who argue for belief formation to be intentional though not governed by intentions; the second way was pursued by Conor McHugh and Pamela Hieronymi who base their position on the analogy of intention (formation) and belief (formation) while accepting doxastic involuntarism to be true. Despite their diverging positions towards the truth or falsity of doxastic voluntarism, the proponents of both ways make heavy use of compatibilist methods borrowed from the free will debate. In both approaches the affirmative position concerning doxastic freedom is based on this conditional: If there is compatibilist free will, there also is free belief. In this article, I will analyse the underlying compatibilist moves for the introduction of free will in the practical debate and their application in the debate on doxastic freedom. I aim at showing that doxastic compatibilists weaken the conditions for freedom and control in a way that makes room for absurd consequences. Doxastic and free will compatibilists, especially those who make use of reason-responsiveness, so I will argue, commit themselves to rather strange sorts of freedom like freedom of fear, freedom of anger and freedom of hope. I will specifically refer to the positions 
of Steup and McHugh who both argue for reason-responsiveness as the main criterion for doxastic freedom, even though they differ with regard to the question of doxastic voluntarism.

Note that this is no attempt to reject the supposed analogy of free will and free belief, nor is it an attack on compatibilism per se. ${ }^{1}$ In fact, I fully agree that the mentioned conditional holds: if there is compatibilist free will, we have all reason to think that there also is doxastic freedom. But the notion of compatibilist free will is as problematic as the notion of a genuine doxastic freedom. The analogy holds because both notions are equally misguided when they are construed as a special sort of freedom that goes beyond freedom of action. This does not mean that I generally think that the agents that are used as paradigm examples for either lacking free will (the addict) or lacking free belief (the paranoid) actually are free agents. Many of these cases are indeed genuine examples of agents who are deprived of their freedom; this is not what I aim at denying. What I deny is that we need an extra sort of freedom in order to handle any possible source of unfreedom. I will argue that mental disorders provide many sources of potential unfreedom and that this fact challenges any compatibilist approach to freedom. In Sect. 4, I will discuss this challenge by pointing out to what consequences doxastic and free will compatibilists commit themselves when they define freedom in terms of reason-responsiveness or other weak forms of control. In the Sect. 5, I will argue that the notion of freedom of action is broad and rich enough to capture all the different sources of unfreedom as a violation of one unified kind of freedom. I will sketch my account of such a unified kind of freedom that makes additional sorts of freedom like free will and doxastic freedom superfluous. This account is of a down-to-earth compatibilist nature.

But first I have say something about practical compatibilism. This part will cost me some space though, given the extent of the debate, I cannot go into details. My main aim in Sect. 2 is to show the development from the classic compatibilists' freedom of action towards the modern notion of compatibilist free will and reason-responsiveness. In Sect. 3, I will discuss compatibilist approaches to doxastic freedom.

\section{Practical compatibilism}

For the most part the free will debate centres around the question of the compatibility of practical freedom and determinism. Theories about practical freedom are divided into two main fields: incompatibilists claim that freedom and determinism exclude each other, while compatibilists contend that freedom and determinism are independent, such that the truth of determinism as such is no threat for freedom. Determinism, very roughly, is the view that there only is one possible future given the past and the laws of nature. Determinism can be spelt out in different ways, but since this is not the topic of the paper, I will not go into much detail here. Suffice it to say that in

\footnotetext{
1 This makes my account differ from Booth's (Booth 2014) critique. Although I think that Booth is right in rejecting doxastic compatibilism, I will not refer to libertarian concepts of action and intentionality in order to make this point. My critique of doxastic compatibilism comes from within the compatibilist doctrine. In order to reject doxastic compatibilism, I do not have to reject compatibilism per se.
} 
a deterministic world it is true now that a person who is not born yet will perform a particular action (e.g. stealing a certain car) at a particular time (e.g. at 4:13 pm on her 21st birthday). If determinism is true, time, space and circumstances of this future action of a future agent who is not born yet are set to the very last detail; and this is so for all events at any time. The compatibilists' job now is to convince their audience that this person, under certain conditions, was free in performing the action in question (e.g. stealing a car) even though this was fixed already before she was born; or, given that the person was not free in doing so, compatibilists have to show that her unfreedom does not result from the truth of determinism, but stems from a violation of some other, freedom relevant condition. Compatibilists often say that for freedom it is not important whether an agent is determined but, if she is, in what way she is determined. This distinction that is drawn between the right and the wrong kind of determination will also play a central role in the doxastic debate.

Note that philosophers who accept compatibilism neither have to be determinists, nor are they committed to the claim that there is freedom. The only consequence of the compatibilist position is that determinism, if true, is insufficient for rejecting freedom. Although most compatibilists claim that (sometimes) we perform actions freely, this is not a consequence that directly follows from their compatibilist view. ${ }^{2}$ In addition to showing that the relevant conditions for freedom are independent from those of determinism, the freedom-affirming compatibilist has to show that these conditions are (sometimes) satisfied by agents in our world. ${ }^{3}$

\subsection{Classical compatibilism}

Which are these conditions for freedom that (sometimes) do apply in our world independently of the possible truth of determinism? For classical compatibilists this question relates to an agent's freedom of action and is not about her freedom of the will. An agent who does as she wants to do and is able to translate her will into action in the absence of physical hindrance is commonly seen as an agent who enjoys freedom of action. Being determined in one's doing by one's own will is the right kind of determination, while being determined by external force is the wrong kind. The challenge that classical compatibilists have to meet is the incompatibilists' worry: if there is only one possible future, an agent never could have done otherwise than she

\footnotetext{
2 Incompatibilism, in the same way, neither commits to indeterminism nor to a position that affirms freedom. Incompatibilists can be divided into libertarians and hard determinists: the former speak out for freedom and reject the truth of determinism, while the latter affirm the truth of determinism and reject freedom, but both share the same incompatibilist position. Compatibilism and incompatibilism unqualified are modal claims without any commitment towards the truth or falsity of determinism and the existence of freedom in our world.

3 While freedom-affirming incompatibilists are called 'libertarians' in reference to liberty, there is no special term for the freedom-affirming compatibilist. In order to distinguish the freedom-affirming compatibilist more sharply from the 'soft determinist,' who is a compatibilist and a determinist, I suggest the term 'freedomist' and 'freedomism'. While a soft determinist may also be a freedomist, the freedomist position does not commit to soft determinism. Since liberty and freedom are used synonymously in this debate, there should be no harm done by reserving freedomism for freedom-affirmative compatibilism and libertarianism for freedom-affirmative incompatibilism.
} 
actually did. How might an agent be free in her $\varphi$-ing if it was fixed that she will do so long before she was born? Being free in $\varphi$-ing seems to imply that the agent could have acted differently than she actually did. And this seems to be precluded by the truth of determinism. The classical compatibilist's response to this problem is to point out that there are different meanings of 'can': the first meaning of 'can' refers to the absence of constraint, while the second meaning conflicts with the truth of determinism. Compatibilists argue that it is the first meaning we should address in a discussion concerning freedom but not the second. The most prominent attempt to provide a compatibilist account of the requirement that an agent could have done otherwise $(C D O)$ is known as the conditional analysis of 'can'. According to this interpretation, an agent could have done otherwise iff she would have done otherwise, had she decided to do so. She did not in fact decide differently, but had she done so, another action would have followed (given that there was no external hindrance). ${ }^{4}$

This distinction is independent from the truth of determinism, because it is not required for an agent that she could have done differently given the same past, but that she could have done differently given that the past with regard to her will was appropriately different.

\subsection{Modern compatibilism: free will compatibilism}

In the last decades, the classical compatibilist position was refined in several respects. It may be more appropriate to say that the classical position was not only refined but was replaced by another compatibilist position I will call 'modern compatibilism' or 'free will compatibilism'. Given the extent of the debate, not all of these developments can be addressed here. I will only address those movements that are essential for compatibilist moves in doxastic freedom. Basically, two connected movements emerged: one gave rise to a compatibilist version of freedom of the will that goes beyond freedom of action; the other is about an agent's responsiveness to the reasons she is given for action. Both movements involve a discussion of the kind of control that is exercised by the agent independently of the truth or falsity of determinism.

\subsubsection{Compatibilist free will}

The central movement within practical compatibilism is the introduction of a compatibilist notion of freedom of the will that is supposed to be superior to the classical concept of free action. Harry Frankfurt was the first who formulated an explicitly compatibilist version of 'free will':

When we ask whether a person's will is free we are not asking whether he is in a position to translate his first-order desires into actions. [...] Rather, it concerns his desires themselves. (Frankfurt 1971, p. 15)

\footnotetext{
4 The conditional analysis of 'can' is attributed most prominently to Moore (1912, 2005) who gave the first detailed analysis of it. But conditional readings of $C D O$ werw used long before that by Locke (1689) and Hume (1739/1740, 2006; 1748, 1999).
} 
Frankfurt gave a very influential example of an agent who does as he wants to do but, intuitively, seems to be an unfree agent after all: the unwilling drug addict. The unwilling addict has a very strong desire to take drugs, but also has the conflicting desire not to take them. Frankfurt analyses the unwilling addict as a person who identifies with the latter desire but who is actually motivated by the former one:

[T] hese desires are too powerful for him to withstand, and invariably, in the end, they conquer him. He is an unwilling addict, helplessly violated by his own desires. (Frankfurt 1971, p. 12)

Frankfurt explains that the unwilling addict's unfreedom lies in his being motivated by an irresistible desire of the first order (to take drugs) he does not want to be effective on the second order. The mismatch of his second order volition and his (effective) first order desire makes the unwilling addict lacking freedom of the will despite doing as he wants to do. Frankfurt concludes that a person who enjoys full freedom not only is required to do as she desires on the first order; additionally the agent is required to have the will she wants to have. In his critique of Frankfurt's hierarchical approach Watson (1999) changes the source of the agent's reflection but sticks to the idea that there can be something wrong with the agent's desires. He explains that the kleptomaniac's thievery is motivated by her desire to steal though she finds no worth in doing so. The urging desire to steal overpowers her evaluative judgement that this is a bad thing to do. In Frankfurt's and Watson's account, the addict and the kleptomaniac fail to control their desires, because they act on a desire they do not approve of or do not identify with. In both approaches it is the irresistible force of the desire that explains why the agent lacks control: this is what Frankfurt and Watson consider to be the wrong kind of determination. The right kind of determination comes from a second order volition (Frankfurt) or from an agent's evaluative judgement about what is worth to do (Watson).

Leaving aside the particular theories, the general idea that there can be something wrong with an agent's desires - something that is relevant for her lacking freedomwas and still is very promising for modern compatibilists. More examples of agents followed who were said to do as they want to do though they are unfree in their wanting: persons who suffer from various sorts of obsessive-compulsive disorders and all other sorts of mental incapacities (that includes children and mentally ill persons). In addition to these cases of mental incapacities, modern compatibilists came up with explanations as to why agents lack freedom when they act under hypnosis or found themselves with alien desires and intentions implanted by evil neurosurgeons. As it seems, the flaws of classical compatibilism were eventually corrected: not only external, that is, physical constraint but also internal constraint in all its varieties can be addressed now.

\subsubsection{Reason-responsiveness}

Another way to address the question of the right and the wrong kind of determination comes from Fischer and Ravizza's position they call 'semi-compatibilism'. This position, inspired by Frankfurt's rejection of the principle of alternate possibilities, rejects an agent's ability to do otherwise as required for moral responsibility. Instead, they concentrate on another kind of freedom they take to be relevant for moral responsibility. In 
order to account for that distinction, they introduce two different kinds of control that fall apart in cases of motivational overdetermination: regulative control and guidance control. While regulative control requires the agent's control over the actual and the alternative sequence (doing $\varphi$ and not doing $\varphi$ ), guidance control requires the agent's control over the actual sequence only. Even if regulative control might be precluded by evil neurosurgeons and by determinism, guidance control is precluded by neither. Fischer and Ravizza argue that "guidance control is the freedom-relevant condition necessary and sufficient for moral responsibility" (Fischer and Ravizza 2000, p. 441, footnote 1) and that "[g]uidance control of an action involves an agent's freely performing that action" (Fischer and Ravizza 1998, p. 31). Guidance control requires that (i) the agent owns the mechanism that leads to her action in the actual sequence and (ii) that this mechanism is moderately responsive to reasons. It is the second feature that will be crucial for the doxastic debate: the condition of reason-responsiveness $(R R)$.

Responsiveness to moral reasons is defined conditionally: an agent's mechanism that leads her to action is responsive to reasons iff it is true that had the agent had access to different reasons in a variation of the actual sequence where the same mechanism is operative and all other things being equal, she would have at least considered these reasons or reacted to them appropriately. ${ }^{5}$ There are different ways of failing to be responsive to reasons: some concern the kind of reason that is to be considered (moral, non-moral, right or irrelevant kind), others relate to the way in which an agent can fail to respond to them (receptivity, reactivity) and it is also crucial what strength of the respective reason is required in order to make the agent respond. According to Fischer and Ravizza, Jim the addict is not responsible for taking drugs when he acts on an irresistible urge to take them. They explain that acting on irresistible urges involves "some physical process of kind $P$ taking place in [the agent's] central nervous system, and that a mechanism of kind $P$ is not reasons-responsive" (Fischer and Ravizza 1998, p. 48). That is why the addict is not morally responsible for the resulting action. Processes that are not responsive to reasons are the wrong kind of determination, while other processes that are reason-responsive are of the right kind.

What makes this account of guidance control to be a promising model for doxastic control is the fact that the agent is not required to exercise any voluntary control over her mechanism and the way she responds to reasons. The responsiveness of the mechanism that leads to action is not a capacity that the agent exercises through her will; $R R$ is better to be seen as a special feature of the process that results in the agent's willing and performing an action. A feature like $R R$ seems to be what is needed to argue for doxastic freedom, too.

\footnotetext{
5 In the précis of their book, Fischer and Ravizza give a brief summary of their notion of moderate reasonsresponsiveness: "A mechanism of kind $K$ is moderately responsive to reason to the extent that, holding fixed the operation of a $K$-type mechanism, the agent would recognize reasons (some of which are moral) in such a way as to give rise to an understandable pattern (from the viewpoint of a third party who understands the agent's values and beliefs), and would react to at least one sufficient reason to do otherwise (in some possible scenario). That is, a mechanism is moderately responsive to reason insofar as it is "regularly" receptive to reasons (some of which are moral), and at least weakly reactive to reasons" (Fischer and Ravizza 2000, p. 444).
} 


\subsection{Problems of practical compatibilism}

Classical and modern compatibilism have one problem they share: both cannot account for cases in which agents choose the lesser evil in a dilemmatic situation, e.g. Aristotle's captain who gets rid of his precious cargo in order to avoid shipwreck or victims of interpersonal coercion as they are known in hold-up or blackmail scenarios. While classical compatibilism simply lacks the means to properly analyse these agents as being deprived of their freedom, modern compatibilists subsume these cases under the notion of lacking free will. The classical compatibilists' inability to analyse these agents as lacking freedom has its origin in the conditional analysis of $C D O$ which provides no help for distinguishing free from unfree action. It cannot draw a distinction, for example, between donating money to a person and surrendering money to a criminal in a hold-up situation. In both cases, the agent could have done otherwise, because for both it is true that they would have done otherwise, had they decided to do so. Since any threat can, in principle, be defeated by accepting the penalty, the counterfactual antecedent "had she decided otherwise" (e.g. to accept the penalty) overwrites the factual presence of the threat that motivates the agent in the hold-up case to surrender her money. The conditional analysis of $C D O$ cannot provide an explanation as to why we consider the hold-up situation as freedom undermining; it can only explain why the agent, in both cases, handed over the money intentionally.

Modern compatibilists challenged the classical approach with the addict's situation: the addict takes the drugs because she wants to do so, but since she is motivated by an irresistibly strong desire, she could not have effectively decided against taking the drug (or would not have carried out her decision). They concluded that an additional sort of freedom is needed in order to account for the addict and other cases of internal constraint. This new sort of freedom is tailored to the very specific phenomenology of an agent who is seen as craving and overwhelmed by her desires. As a consequence, modern compatibilists have either no room for normal cases of coercion and dilemmatic situations, or they have to interpret them such that they fit these phenomena. Frankfurt and Watson analysed coerced agents as acting on an irresistible desire which they either do not identify with (Frankfurt) ${ }^{6}$ or which they consider to be not worth acting on (Watson). I find it highly problematic to describe a person who is driven by the admittedly strong desire to survive a hold-up as not identifying with this desire or as not finding any worth in it. If the victim identifies with any desire of hers, it certainly is the desire to rescue her life; and rescuing one's life clearly is something she finds maximally worth doing.

Fischer and Ravizza split the Aristotelian captain into two cases: they explain that the captain lacks the freedom relevant condition for moral responsibility only if he is overwhelmed by panic and acts on a mechanism that is not responsive to reasons: he

\footnotetext{
${ }^{6}$ Frankfurt (1988,p. 41f, my italics): "An offer is coercive, on the other hand, when the person who receives it is moved into compliance by a desire which is not only irresistible but which he would overcome if he could. In that case the desire which drives the person is a desire by which he does not want to be driven. When he loses the conflict within himself, the result is that he is motivated against his own will to do what he does. [...] his will when he acts is a will he does not want to be his own. He acts under a compulsion which violates his own desires."
} 
"panics in a storm and is impelled to jettison his cargo by an irresistible fear" which is "a forced action because the mechanism that produces it is not responsive to reasons" (Fischer and Ravizza 1998, p. 82). In contrast to this, a calm skipper who gets rid of the cargo because this is the sensible thing to do, is free and responsible (though maybe not blameworthy) because he appropriately responds to reasons. The same distinction has to be made, so Fischer and Ravizza, for a bank clerk in a hold-up. Since the clerk's and the captain's situation do not necessarily involve irresistible desires and irrationality, Fischer and Ravizza have to locate these patterns by adding details to the example that match their theory. But this certainly is no explanation as to why interpersonal coercion or dilemmatic situations are seen as freedom undermining. This judgement is made independently of an agent's irrationality. What is achieved with Fischer and Ravizza's analysis is the distinction between an irrational reaction and a rational one, given the same coercive circumstances. It is unclear why this should be the right way to account for the kind of freedom the captain and the clerk lack. I will argue that doxastic freedom modelled on this account to free will is prone to the same weakness as its template: it cannot provide criteria for free and unfree doxastic agency that go beyond rationality requirements. Mental disorder and irrationality is the wrong place to look for conditions that undermine an agent's freedom.

In the next section, I will discuss two compatibilist approaches to doxastic freedom that rest on the application of reason-responsiveness. In Sect. 4, I will show what consequences result from this approach to doxastic freedom.

\section{Compatibilist approaches to doxastic freedom}

In contrast to the practical debate, the question concerning doxastic freedom is not a question that explicitly relates to the truth or falsity of determinism. The leading question in the doxastic debate is not whether the control required for doxastic freedom is compatible with determinism, but whether there is a sensible notion of doxastic freedom and the control needed for it given our mental capacities. So doxastic compatibilism is not, as one could think, the position that the truth of determinism does not preclude doxastic freedom. Since it is the lack of voluntary control over doxastic attitudes that threatens doxastic freedom, the parallel doxastic compatibility question rather seems to be: Is doxastic freedom compatible with the truth of doxastic involuntarism? This is to ask whether we can be free in or in control of our doxastic states if we lack voluntary control over them. For doxastic involuntarism is neither committed to determinism nor to indeterminism, the truth or falsity of determinism does not play a significant role here. Of course, the threat doxastic involuntarism poses can be formulated as a threat that has its origin in determinism by arguing that, in a deterministic world, epistemic reasons determine our doxastic attitudes in the same way as practical reasons determine our actions. According to this picture, one could say that if determinism is true, agents are unfree in their actions and in their doxastic attitudes. But this only is a possible interpretation and nothing the doxastic involuntarist is committed to. It seems that the worry that comes with doxastic involuntarism with regard to doxastic freedom is of another quality than the threat of determinism for practical freedom: the fact that beliefs are gov- 
erned by something that is not only from the deterministic perspective outside the agent (e.g. the evidence the agent is given) is a more general problem for doxastic freedom than the (supposed) fact that the agent's practical considerations are determined by events that took place long before she is born. Practical considerations are not as such a threat for practical freedom, because they are the agent's own considerations. It is the possible truth of determinism that endangers practical freedom, because then the agent's own considerations can be traced back to something external to her. The truth of doxastic involuntarism, on the other side, is considered a threat for doxastic freedom whether or not determinism is true. So determinism is not the problem in this debate on freedom. But is the role of doxastic involuntarism in the doxastic debate really analogous to the role of determinism in the practical debate?

For sure, the question whether doxastic freedom is compatible with doxastic involuntarism is one central question in the debate. However, this again is not the relevant question one has to affirm in order to count as a 'doxastic compatibilist'. Were that the case, Steup's and Ryan's accounts would turn out to be doxastic incompatibilist, since both defend doxastic voluntarism as required for doxastic freedom and thereby accept the incompatibility of doxastic freedom and doxastic involuntarism; this would be a doxastic "libertarian" position. Both, Ryan and Steup, claim that we intentionally and freely form beliefs; both are doxastic voluntarists. Disregarding this fact, their accounts are described as compatibilist; not only by themselves but also by others, e.g. by Nottelmann (2006), Booth (2014) and Peels (2013). As they do, I will subsume Steup's and Ryan's approach under 'doxastic compatibilism' as well, because Steup and Ryan borrow the methods from practical compatibilism in order to argue for doxastic voluntarism and additional conditions that they take to be jointly sufficient for doxastic freedom. Their main aim is to show that practical compatibilists provide criteria that are also applicable to the doxastic domain.

I am going to discuss the application of these methods as 'doxastic compatibilism' knowing that there is nothing genuinely compatibilistic in the sense of a reconciling project of doxastic freedom with either doxastic involuntarism or determinism. The central compatibilist method that is used in order to account for doxastic freedom is an epistemic version of Fischer and Ravizza's reason-responsiveness. I will briefly discuss Steup's and McHugh's approach to doxastic freedom with regard to the compatibilist methods that are used, on the one hand, and by focusing on the paradigm cases of agents who lack doxastic freedom, on the other. I will ask whether these cases can play the analogous role to the addict and the kleptomaniac. It is important to look at the cases because there is a very natural and broad understanding when it comes to the violation of an agent's freedom. This can be used to find a pattern in order to define conditions that have to be present or absent for freedom (e.g. various forms of constraint). Especially for compatibilist methods it is required to find cases of agents that clearly lack freedom of the respective sort that shall be analysed. Compatibilist conditions for freedom of any kind are useless if they do not provide any criterion for making distinctions within the group of the objects (actions, desires, beliefs etc.) of the respective kind of freedom. For there being freedom, there also has to be a way for lacking freedom. 


\subsection{Steup's reason-responsiveness}

The central compatibilist criterion Steup borrows from the free will debate for his account of doxastic freedom is the notion of reason-responsiveness $(R R)$ that he applies to the formation of doxastic states. On the one hand, he needs $R R$ for his voluntarist account when he defines weak intentionality in order to establish an analogy of belief and action. On the other hand, $R R$ is a necessary condition for doxastic freedom in addition to weak intentionality:

S's attitude A toward $\mathrm{p}$ is free iff (i) $\mathrm{S}$ has attitude A toward $\mathrm{p}$, and (ii) $\mathrm{S}$ 's attitude A is weakly intentional; (iii) S's having taken attitude A toward p is the causal outcome of a reason-responsive mental process. (Steup 2008, p. 385, my italics)

Other passages even seem to suggest that, for Steup, $R R$ alone is sufficient for doxastic freedom:

By far most of our doxastic attitudes meet the condition of reason-responsiveness. That gives us a reason to think that most of our doxastic attitudes enjoy freedom of the compatibilist kind. (Steup 2008, p. 381, my italics)

Disregarding the question what role $R R$ exactly plays in Steup's account and whether it is promising to use it as a condition for weak intentionality, $R R$ undoubtedly is the central factor for his notion of doxastic freedom. Doxastic attitudes that are the outcome of a process that is responsive to epistemic reasons are determined in the right way and therefore free; accordingly, doxastic attitudes that are the result of a process that is not responsive to epistemic reasons are determined in the wrong way and therefore not free.

In order to apply $R R$ to the doxastic domain in analogy to $R R$ in the practical field, Steup argues against the view that only practical reasons and intentions give rise to voluntary control. He brands proponents of doxastic involuntarism, e.g. Bennett, to be "chauvinistic" when favouring practical reasons over epistemic reasons; he further calls the rejection of epistemic reasons as constituting voluntary control to be "ad hoc" (Steup 2008, p. 388) and not well argued for. Since automatic actions like "shifting the gear' or 'unscrewing the cap of one's toothpaste' are performed intentionally without there being an intention for doing so involved, Steup concludes that the concept of intentionality we need in the practical domain is a weak one anyway, and that the normal formation of beliefs easily meets its demands. According to Steup, weak intentionality requires two conditions (NAPA conditions) to be met: X-ing is weakly intentional iff it is not accidental (NA) and accompanied by a pro-attitude (PA). Actions as well as beliefs usually meet these conditions:

Consider once again my belief that I have hands. Clearly my belief meets the NAPA conditions. [...] I don't believe I have hands due to cognitive dysfunction. So my belief is not accidental. Moreover, my belief is accompanied by a proattitude. I'm comfortable with it; I endorse it; I don't feel bad about it in any way. (Steup 2008, p. 385) 
What is wrong with agents who lack doxastic freedom according to Steup? Steup contends that agents who have "[a]ttitudes that are the causal outcome of deviant psychological conditions such as neurotic compulsion, phobia, paranoia, and the like" (Steup 2008, p. 381) lack doxastic freedom, because they do not respond to reasons in the right way and their attitudes are accidental in that sense. In order to motivate the need for doxastic freedom, Steup refers to agents suffering from mysophobia: the compulsive hand-washers Albert and "Mysophobic Mel" (Steup 2012).

[Albert] believes that there are dangerous germs on his hands even though he just washed them. Because of his neurotic compulsion, he will believe this in a wide range of alternative situations, no matter how good his evidence is for believing otherwise. (Steup 2008, p. 380)

Surprisingly, Steup uses the same Albert in an earlier passage as an example that emphasizes the importance of freedom of the will in addition to freedom of action. He describes Albert as performing an "unfree action because Albert is messed up about what he wants" (Steup 2008, p. 376, my italics). Steup accepts the modern compatibilists' rejection of the classical approach when he says that "[ $t$ ]he example of Albert shows that what matters for freedom is not only that we can act according to the determinations of the will, but that the will itself be free" (Steup 2008, p. 376, my italics). This is surprising insofar as it is Steup's main aim to argue for the analogy of action and belief, rather than the analogy of desire or intention and belief. According to Steup, an agent is free in performing an action iff the agent enjoys freedom of action and freedom of the will, but it is the free will condition in terms of $R R$ that seems to be crucial for his account of doxastic freedom. ${ }^{7}$

Unfortunately, it is unclear whether Steup thinks that Albert is a paradigm case for unfree will or for unfree belief, or maybe for both. What exactly is the freedom undermining source of Albert's illness? What is the target of his "neurotic compulsion"? Is it his unalterable belief or his irresistible desire that makes him an unfree agent? Is Albert incapacitated in both, his beliefs and his desires? Or is it required for Steup's account that cases of lacking doxastic freedom are at the same time also cases of lacking free will? In order to find a paradigm case for doxastic freedom, it might be good to look for other examples of agents who lack doxastic freedom that are not also cases of practical unfreedom. Unlike Albert, the person who suffers from paranoid delusion seems to be such a case of genuine doxastic unfreedom. I will discuss this suggestion in the next section.

\subsection{McHugh's reason-responsiveness}

In the introduction I referred to two ways of avoiding the threat of doxastic involuntarism for doxastic freedom. Steup and Ryan want to uphold doxastic voluntarism and argue for other forms of voluntary control than through intentions and practical reasons. Steup tries to convince us of free beliefs being weakly intentional and caused

\footnotetext{
7 It is unclear what the exact analogous conditions are for free belief and whether there is the same double condition, but I will not discuss this problem in this paper. This has to be done somewhere else.
} 
by a reason-responsive process. Still, the analogy between belief formation and acting remains problematic and was criticized in many respects. A recent move in the doxastic debate supports the involuntarist's rejection of the analogy of belief and action, but models doxastic freedom in analogy to freedom of intention. Representatives of that view accept the involuntarist's position concerning the lack of voluntary control over doxastic attitudes, but deny that this necessarily undermines doxastic freedom. As McHugh puts it:

We do not have voluntary control over our doxastic states, but voluntary control is not required for doxastic freedom. Doxastic freedom is analogous to freedom of intention, not to freedom of action. (McHugh 2011, p. 35)

McHugh does not only accept the involuntarist's position that there is no voluntary control over doxastic attitudes, but argues that "if we had voluntary control of intentions or of doxastic states, this would actually undermine our freedom” (McHugh 2011, p. 1) and that the "role of doxastic states in the regulation of intention is such that our lack of voluntary control over our doxastic states enriches our freedom, rather than taking away from it" (McHugh 2011, p. 34). McHugh illustrates this point with a variation of Alston's original example inspired by Kavka's toxin puzzle ${ }^{8}$ :

For example, if you had voluntary control over your beliefs, you would form the belief that the US is still a colony of Britain, if offered an immense reward to believe it. Suppose you were then planning a trip to the US from Britain, and had to decide whether to take your passport. If the US is a colony of Britain, you don't need your passport. And it's a pain to bring your passport if you don't have to. So, you would form the intention not to bring your passport, and, other things equal, you would not bring it. All this despite the fact that you have excellent reasons to bring your passport. This would not be cause for congratulation. (McHugh 2011, p. 34)

If voluntary control is not the sort of control that is required (or even compatible) with doxastic freedom, what kind of control does McHugh think is needed for doxastic freedom? Although he rejects Steup's account of doxastic voluntarism, McHugh makes use of the same compatibilist method and applies Fischer and Ravizza's concept of reason-responsiveness to the regulation process of doxastic attitudes. Freedom of intention and doxastic freedom are analogous, because both involve receptivity and reactivity to reasons. The crazed killer "is unreceptive to reasons for or against $\phi$-ing [and] would recognise only some very specific and arbitrary consideration as a reason not to $\phi$." This is why the crazed killer's "intention to $\phi$ will not count as free" (McHugh 2011, p. 18). In perfect analogy, McHugh suggests that "an individual with a paranoid delusion that $p$ might be such that she would recognise only some very specific and arbitrary consideration as evidence against $p$." And because of this lack of receptivity to the evidence the delusional believer's "doxastic state [...] will not count as free" (McHugh 2011, p. 26). The same analogy is stated for the unfreedom that results from lacking the capacity to react to the reasons one is receptive

8 See Kavka (1983). 
to. An agent who "compulsively intends to $\phi$ [e.g. to pick up red objects (McHugh 2011 p. 12)]" is unfree in her intention because she "lacks the capacity to react, in her intentions, to the reasons she recognises for or against $\phi$ ing" (McHugh 2011, p. 18). Analogously, "Freudian cases of repressed beliefs" render the agent incapable "to react on the (putative) evidence she recognises for or against p" (McHugh 2011, p. 26). Modelling doxastic freedom on freedom of intention in this way, so McHugh, provides us with a notion of doxastic freedom that "can plausibly ground epistemic responsibility" (McHugh 2011, p. 13). Because freedom of intention "does indeed merit the name of freedom" (McHugh 2011, p. 13), doxastic freedom does so, too.

It seems plausible that there is an analogy here and the example of the delusional believer can play the same role as the addict and the kleptomaniac did in the practical debate. Persons who believe that they are followed by aliens or the CIA seem to be constrained in their doxastic life. They believe that their food is poisoned, their activities watched, their home wired and that people on the street spy on them. This is a distressing way to look at the world. These people spend a lot of effort to avoid situations of apparent danger; they don't go to supermarkets for shopping and only accept food from trusted relatives, they install considerable amounts of anti-spy equipment to make their homes safe and they avoid going out too often. Other persons who try to convince the delusional believer that there is evidence against her beliefs are mistrusted and believed to be part of the conspiracy. As it seems, these persons are captives of their own false and irrational beliefs which they are unable to give up. The source of their unfreedom is to be identified solely within their beliefs. Agents who suffer from paranoid delusion seem to be paradigmatic cases for doxastic unfreedom. The existence of these agents seems to give us sufficient reason to consider the introduction of a new sort of freedom that concerns our doxastic attitudes.

\section{Sources and sorts of freedom}

Different sources of unfreedom as we find them in the different cases I described before could hint at different sorts of freedom that are violated in the respective cases. Cases of unfreedom where a physical source can be identified that constrains the agent's body and her ability to act, e.g. when a person is tied up, hint at the violation of this person's freedom of action. Irresistible desires and urges as the addict, the kleptomaniac and the compulsive hand-washer are supposed to suffer from, are psychological sources concerning the agent's motivation that hint at the absence of freedom of the will. Another psychological source that can be related to an agent's unfreedom seems to lie in having irresistibly strong beliefs that do not properly respond to evidence: a phenomenon that is ascribed to persons who suffer from paranoid delusion and schizophrenia. This seems to suggest that persons with paranoid delusion lack doxastic freedom. Indeed, mental disorders and incapacities are promising targets for the compatibilist to look for difference makers that are needed to distinguish normal from unnormal (mental) behaviour. Further understanding of how certain mental disorders work helps to identify these different sources of an agent's unfreedom. As we saw, a compatibilist version of freedom of the will is needed because the classical theory of freedom of action cannot explain why the addict and the kleptomaniac are deprived 
of their freedom; further, doxastic freedom is required because neither the conditions of free will nor the conditions of free action are violated in the case of the delusional believer despite the fact that we intuitively judge that this person is an unfree agent. This suggests that we need to allow for this further sort freedom in addition to freedom of action and free will so that the full range of human freedom is covered.

Let's have a look at another form of mental disorder: persons who suffer from anxiety disorder experience excessive and irrational fear even in situations which are objectively not dangerous. Phobias are a special kind of anxiety disorder, e.g. when persons irrationally are afraid of animals (arachnophobia, cynophobia) or persons who panic in open and public places (agoraphobia). Suffering from a phobia means to suffer from severe constraints in one's daily routine: these persons plan their lives around their phobias in order to avoid situations in which they face the object of their fear. In order to avoid panic attacks caused by wide open places and crowds, the agoraphobic isolates herself at home. Cynophobics fear meeting a dog so much that they avoid going for walks in parks. Arachnophobics avoid camping, travelling to foreign countries and they ritually check their bedding and clothing for spiders. None of these agents are in control over their fear and without doubt, these persons are deprived of their freedom. Compatibilists should be able to explain why we regard persons who suffer from anxiety disorder to be unfree agents, just as we do with regard to the addict and the kleptomaniac. Unfortunately, free will, free action and free belief do not provide us with appropriate conditions that are undermined by anxiety disorder. It seems that we need something more specific to account for these cases.

\subsection{Freedom of fear}

Imagine the philosophical position of anxiotropic voluntarism: it is the position that we have voluntary control as to whether we are afraid or not. According to this view, we can shut on and off our fear states as we like and, therefore, we enjoy freedom of fear. But this position will not have many advocates. Most people will consider themselves what we may call an anxiotropic involuntarist, because it seems implausible that we are in direct voluntary control as to whether we are afraid or not. Fear states, so the common anxiotropic involuntarist, are not caused by intentions or practical considerations, but solely bear on the assumed presence or absence of appropriate objects of fear. However, so the imagined proponent of anxiotropic voluntarism could respond, fear states are weakly intentional according to Steup's NAPA conditions: they are non-accidental and are accompanied by a pro-attitude. Our imagined anxiotropic voluntarist may echo Steup's explanation: I don't fear the armed criminal due to cognitive dysfunction. So my fear state is not accidental. Moreover, my fear state is accompanied by a proattitude. I'm comfortable with it; I endorse it; I don't feel bad about it in any way. ${ }^{9}$ But

\footnotetext{
9 This is a reformulation of Steup's explication why his belief that he has hands satisfies the NAPAconditions in terms of fear with regard to an armed criminal (see Steup 2008, p. 385). Note that the pro-attitude in both cases cannot to be seen as being comfortable with the content of the respective state. Of course I feel bad, in some other sense, about facing an armed criminal but this would also be true for the content of my belief that I have no hands anymore, e.g. after an accident. What I am comfortable with is how I came to believe that I do not have hands anymore or that I fear the armed criminal.
} 
the involuntarists about fear will probably remain unconvinced. Fear states, so they will say, are not like actions; we cannot, just like that, stop being afraid in a situation in which we still face the object of our fear. And maybe some anxiotropic involuntarist invites her audience in an Alstonian manner to try fearing the chair they sit on just by deciding to do so. Certainly, most people will agree that we permanently lack control over our fear states and, therefore, also lack freedom of fear.

But we could imagine a new compatibilist move in philosophy that does justice to our involuntarist worries: anxiotropic compatibilism. Fear states, so this new move may claim, are not like actions; indeed, we have no voluntary control over them. However, the imagined anxiotropic compatibilist may say, this is not the end for freedom of fear: we do not need anxiotropic voluntarism for our fear states to be free. Actually, anxiotropic voluntarism would undermine our freedom and it is an important feature of fear states not be controlled voluntarily. Just imagine what would happen if people could shut off their fear states as they wish. There would be far more accidents in the world because people would not be afraid anymore in dangerous situations. Suppose a bank clerk is afraid of guns and shuts off his fear because he was offered an immense reward for doing so. Years later, he faces a bank robber who points a gun to his head and tells him to hand over the bank's funds. Since the clerk does not fear the gun despite having excellent reasons to do so, he is not doing as told by the robber and, as a consequence, gets shot. This, the anxiotropic compatibilist could say following McHugh, would not be cause for congratulation.

Now the anxiotropic compatibilist could proceed that albeit we permanently lack voluntary control over our fear states, we can enjoy freedom with regard to our fear states and the formation of these. This kind of freedom cannot be modelled on freedom of action, but rather on freedom of intention. Like intentions, fear states are not controlled by the agent's intentions or practical considerations. And although these are not under the agent's voluntary control, this does not mean that they are not under her control at all. They are simply controlled differently. What makes an agent free with regard to her fear states is that the mechanism that leads to them is responsive to reasons. While intentions are responsive to practical reasons (and beliefs are responsive to epistemic reasons), fear states are responsive to anxiotropic reasons: anxiolytic reasons play a role in processes that block the formation of fear states as well as in processes that result in an agent's giving up her present fear state; anxiogenic reasons, on the other hand, play a role in the formation of fear states. ${ }^{10}$ It seems reasonable to say that agents guide and regulate their fear states in accordance to the anxiotropic reasons they have. In a situation in which an armed person approaches an agent, she rationally forms a fear state in response. Once the armed person is removed by the police, she regulates her fear states accordingly.

The normal acquisition, inhibition and extinction of fear admittedly looks like a mechanism that is responsive to reasons. The fact that we expect rational persons to be afraid in dangerous situations and not to be afraid in innocuous situations clearly shows that the anxiotropic compatibilist's claim is not completely off the mark. Indeed, we consider an agent who panics at the sight of a toothless puppy or a harmless house

10 Likewise, anxiogenic drugs are used to increase anxiety in patients, while anxiolytic drugs are used to inhibit or to eliminate anxiety. 
spider to be irrational; and we think the same of an agent who does not show any sign of fear when the plane she sits in is about to crash. People with irrational fear (e.g. patients with anxiety disorder) or the abnormal lack of fear in obviously dangerous situations (e.g. psychopaths, patients with Urbach-Wiethe disease), so the anxiotropic compatibilist argues convincingly, are violated in their freedom of fear because they do not respond properly to the anxiotropic reasons they are given.

But what exactly may count as an anxiotropic reason? What is it that plays the crucial role of guiding and regulating the acquisition, inhibition or extinction of fear states? And what is it that persons with irrational fear or the abnormal lack of it do not respond to? The anxiotropic compatibilist may suggest that objective information about the world or evidence about the presence or absence of danger plays that role. Experimental findings seem to support this view: the amygdala, a part of the brain that controls emotional responses in general and also defence responses in threatening situations, can be influenced by the prefrontal cortex and vice versa. LeDoux (2002) summarizes the results of experiments about fear regulation that bear on the communication of these two parts of the brain:

Pathological fear, then, may occur when the amygdala is unchecked by the prefrontal cortex, and treatment of pathological fear may require that the patient learn [sic] to increase activity on the prefrontal region so that the amygdala is less free to express fear. Clearly, decision-making ability in emotional situations is impaired in humans with damage to the medial and ventral prefrontal cortex, and abnormalities there also may predispose people to develop fear and anxiety disorders. These abnormalities could be due to genetic or epigenetic organization of prefrontal synapses or to experiences that subtly alter prefrontal synaptic connections. Indeed the behaviour of animals with abnormalities of the medial prefrontal cortex is reminiscent of humans with anxiety disorders: they develop fear reactions that are difficult to regulate. Although objective information about the world may indicate that a situation is not dangerous, because they cannot properly regulate fear circuits, they experience fear and anxiety in these safe situations. (LeDoux 2002, p. 217)

This could explain why the arachnophobic freaks out by the sight of an objectively harmless house spider at the other side of the room or in a picture. The fight-or-flight response is initiated in the hypothalamus after a threat was identified in the amygdala due to memory checks concerning earlier emotional responses to a similar stimulus. In contrast to healthy persons, the fight-or-flight response during the phobic reaction cannot be turned off by considering the objective information or evidence that speaks against a real threat: the agent "cannot properly regulate fear circuits" by increasing "activity on the prefrontal region." As it seems, the arachnophobic does not properly respond to the evidence that a house spider's fangs cannot penetrate human skin, that their venom is not dangerous to humans or that a picture of a spider poses no threat at all.

Given this description of phobic patients the anxiotropic compatibilist faces a serious problem: would it not be reasonable to say that the unfreedom involved in arachnophobia actually is a case of doxastic unfreedom? Since the arachnophobic does not respond properly to the evidence "out there," his failure seems to be that 
he does not regulate his doxastic states in accordance to the epistemic reasons he is given. It seems that the arachnophobic irrationally clings to the irresistible belief that the house spider is dangerous and could possibly kill him. Freedom of fear, therefore, seems to reduce to doxastic freedom; and anxiotropic reasons are nothing more than epistemic reasons, or so it seems. ${ }^{11}$ In order to make a stronger case of freedom of fear, our imagined anxiotropic compatibilist should insist that this is not what psychology tells us about phobic persons. Most patients who suffer from a phobia are aware of the fact that their fear response is inappropriate and irrational: the arachnophobic knows that house spiders are not dangerous and that spiders on photographs are not real; nevertheless, he forms a fear state by the mere sight of the picture. The arachnophobic does not actually believe that the spider in the picture is real and can harm him-arachnophobic persons are perfectly able to form their doxastic states in accordance to the epistemic reasons they are given. It is their fear response that is inappropriate given the (appropriate) beliefs they have. For a person who does not suffer from phobias it is very hard to understand why the phobic is afraid of an object that is known not to be dangerous, e.g. when the arachnophobic panics at the mere sight of a photograph that shows a spider and cannot calm herself down by appealing to the knowledge that this is just a picture and not a real spider. In order to make a stronger case, the anxiotropic compatibilist should insist that an agent's freedom of fear can be violated independently of her being doxastically unfree.

As we saw, anxiotropic reasons are not necessarily epistemic reasons since an agent can regulate her beliefs rationally according to the epistemic reasons she is given without thereby being able to regulate her fear state in accordance to the same epistemic reasons. That an agent's beliefs about the presence or absence of danger rather than the actual presence or absence of danger plays the crucial role in rational fear regulation seems to be supported by an experiment Elizabeth Phelps conducted: very abstract verbal information about an aversive event (e.g. mild electric shock) following a neutral event (e.g. sight of a specific geometric figure) can be processed by the amygdala such that a fear response occurs during the neutral event without actually experiencing a dangerous situation linked to this event. ${ }^{12}$ These finding give rise to the following interpretation: in healthy subjects, the mere belief of being in a dangerous situation without ever having experienced any danger in similar situations is sufficient to form a fear state; likewise, the belief that there is no danger (any more) very often also suffices to calm oneself down and give up the fear state one is in. Beliefs about being or not being in danger seem to influence the acquisition or extinction of fear disregarding as to whether these beliefs match reality. Therefore, a healthy agent's beliefs as to whether she is or is not in danger function as anxiotropic reasons that regulate her fear states. Persons who suffer from anxiety disorder or the abnormal lack of fear are not responsive to their own beliefs that they are or are not in danger.

\footnotetext{
11 Thanks to an anonymous referee who suggested that freedom of fear may be reduced to doxastic freedom.

12 Phelps (2004, p. 200): "In an fMRI study, subjects were told that they would receive one or more mild shocks to the wrist, but only when a blue square was presented. Although no shocks were actually presented, subjects showed an arousal response during presentation of the blue square as well as activation of the left amygdala."
} 
It seems that the anxiotropic compatibilist made her point in arguing for freedom of fear as a genuine and non-reducible sort of freedom we need to address in order to account for the full range of human freedom. Compatibilists who do not allow for anxiotropic reasons because they only accept practical (and epistemic) reasons are guilty of chauvinism and their rejection of freedom of fear is ad hoc. They lack sufficient arguments for denying that there is freedom of fear when they allow for compatibilist free will and doxastic freedom spelt out in terms of reason-responsiveness.

\subsection{From sources to sorts}

Reason-responsiveness is a promising tool to account for rationality in the practical and the doxastic field. But reason-responsiveness can be applied to far more mental states than only intentions and beliefs. In the last section, I introduced the anxiotropic compatibilist's argument for freedom of fear that echoes the argumentation that was used for doxastic freedom: if there is compatibilist freedom of intention (and belief) in terms of reason-responsiveness, nothing stands in the way of compatibilist freedom of fear in terms of reason-responsiveness. When the responsiveness to epistemic reasons is a criterion to distinguish freely formed beliefs from those that are formed unfreely, the same can be applied to fear states. As doxastic states, anxiotropic states normally respond to reasons, provided that the person holding them does not suffer from mental disease. Persons who suffer from anxiety disorder seem to be unfree in their fear states in the same sense as the paranoid person is unfree in her doxastic states: both do not respond to the respective reasons appropriately. Therefore, cases of anxiety disorder support the need for an additional sort of freedom that concerns our fear states just as the paranoid supports the idea of doxastic freedom and as the addict supports the need for free will.

But fear states are not the only mental states apart from intentions and beliefs that normally respond to reasons while the formation and regulation of which can be affected by a mental disease. We could go on with esperantic reasons and freedom of hope that is lacked by the Pollyanna and the confirmed pessimist or persons that suffer from severe depression; and we could tell a story about effervescentic reasons and freedom of anger which are lacked by the pathological choleric or persons suffering from intermittent explosive disorder. The new Diagnostic and Statistical Manual of Mental Disorder (DSM-V) lists more than 300 examined mental disorders. It would be a lot of work for philosophy to account for all types of mental disorder that incapacitate an agent in one aspect of her mental life and to introduce new sorts of freedom for each of them. Surely, this is not the idea of compatibilist freedom. However, doxastic compatibilists who refuse to accept these additional forms of freedom are, when judged by their own standards, guilty of 'doxastic chauvinism' that unduly favours doxastic attitudes over other mental attitudes. As it seems, you can have doxastic compatibilism only if you also accept anxiotropic, esperantic and effervescentic compatibilism, and many more. According to this complication, it seems sensible to reject doxastic compatibilism that is based on mere reason-responsiveness. But there is even more to give up. Recall that the analogy was modelled on an approach to freedom of the will (or freedom of intention) that makes use of the responsiveness to practical reasons. 
If one really affirms the analogy of free will and free belief, and further agrees that doxastic freedom commits to problematic sorts of freedom, then the same applies to the concept of free will that served as a template on which doxastic freedom was modelled. The very same conditional that is used to argue for compatibilist doxastic freedom can be held against compatibilist free will: if we accept compatibilist free will, then there also is doxastic freedom (and many more sorts of freedom). In order to avoid the problem of many different sorts of freedom like freedom of fear, freedom of anger, freedom of hope etc., we should take into consideration that compatibilist free will as responsiveness to practical reasons is misguided in the same sense as doxastic freedom and freedom of fear are.

So, what is the problem with reason-responsiveness? The fact that reasonresponsiveness can be applied to far more mental states than intentions and beliefs is, seen alone, not necessarily a problem. On the contrary, it seems to be most welcome that an agent's responsiveness to reasons can be used as a unified tool to analyse rationality with regard to the whole spectrum of our mental life. It is doubtful, however, that facts about an agent's rationality with regard to her mental states will tell us something about an agent's freedom and her control with regard to these mental states. Even if irrationality plays a role in those cases in which mentally ill persons are deprived of their freedom, it alone is not freedom undermining. The fact that reason-responsiveness can be applied to far more mental attitudes than we are willing to regard as apt objects for freedom, should make us very cautious concerning compatibilist attempts to free will and free belief. The compatibilist strategy to spell out freedom in terms of reason-responsiveness weakens the requirements of freedom so that restrictions concerning our intentional or voluntary influence on mental attitudes vanish. But these weakened requirements are far too weak and that is why they can be applied to many mental attitudes besides intentions and beliefs.

We seem to face a dead end here: On the one hand, addicts, kleptomaniacs and delusional believers constitute intuitive cases of unfree agents and it seems right that compatibilism should be able to make sense of these. On the other hand, we end up with freedom of fear, freedom of hope and other odd sorts of freedom when we allow for reason-responsiveness for doxastic states in analogy to intentions, because the same analogy can be used for many different mental states. Of course, the doxastic freedomist could look for further criteria in addition to reason-responsiveness such that they only apply to doxastic states but not to other mental states. But if we want a theory of freedom that is also able to account for unfree agents like those suffering from anxiety disorder without introducing the concept of freedom of fear, I think that there is a more elegant solution. What we need is a unified theory of freedom that accounts for all the different cases of unfree agents without thereby generating new sorts of freedom for each type. In this enterprise, the leading question concerns the unifying structure that is shared by all these different cases of unfree agents. This structure must be applicable independently of the respective source to which the agent's problem can be traced back in the particular case. I think that this can only be achieved by spelling out freedom of action in a broader way than it has been done so far. In the next section, I will explain why I think that the addict, the kleptomaniac, the compulsive hand-washer, the delusional believer and the person suffering from anxiety disorder are unfree in what they are doing. They are unfree due to the same 
structure as victims of interpersonal coercion (e.g. in a hold-up or blackmail situation) and persons in dilemmatic situations (e.g. the Aristotelian captain). Albeit all these agents lack freedom of the same sort, that is freedom of action, the source of their being in such a situation differs and can be traced back either to a certain type of mental disorder, addiction or external circumstances. Note that this approach is not about separating the practical and the doxastic sphere, but is about separating actions from mental states in general. Actions are different: an agent's actions are apt objects for freedom while an agent's mental states are not.

\section{Freedom of action}

After a long excursus to many new kinds of freedom, we finally are back with the only freedom that is worth its name: freedom of action. I take it to be absurd that the choleric is unfree because she lacks freedom of anger, that the person suffering from anxiety disorder is unfree because she lacks freedom of fear and that the Pollyanna and the confirmed pessimist are unfree because they lack freedom of hope. In the same sense, I take it to be absurd that the delusional believer lacks doxastic freedom and the addict lacks freedom of the will. However, these agents may actually be unfree. But they are not lacking a special sort of freedom that is tailored to their respective mental disease or incapacity, no. They are unfree in what they are doing in a specific situation. Sure, it is their disease or addiction that is the source of their problem, but this alone does not make the agent unfree. People with a mental disorder, e.g. an excessive fear of snakes, can live undisturbed by this disease for years when they do not face the object of their fear. It would be odd to relate to them as hypothetically unfree agents, just because they would react in an irrational way, were they confronted with a snake. In addition to the mere existence of the disease, we need a specific situation that brings the respective mental problem to the surface such that it influences the agent's behaviour and course of action. I will sketch my own account of free agency in the following. ${ }^{13}$

What do all the cases mentioned so far have in common that amounts to a unifying structure? I will argue for the claim that the addict, the delusional believer, the person suffering from anxiety disorder and the Aristotelian captain perform an action against their own will. This does not mean that they act against their intentions to do something else, but that they intentionally perform an action which violates a desire of theirs and does so in painful awareness of this fact. ${ }^{14}$ An action that is done unwillingly in this sense involves a conflict within the agent's desires. This does not necessarily mean that the agent has irrational desires (if there is such a thing) or lacks a kind of control over her desires she normally enjoys; it rather is a general and perfectly normal feature of our desires that they sometimes are in conflict with each other. This is nothing to worry about and certainly nothing that makes us unfree. In order to meet the demand of unfree action, a conflict has to take the form of a dilemma for the agent about what

\footnotetext{
13 Given the limited space of this paper, I can only sketch my account of free agency. In an unpublished draft (Wagner 2015), I argue in more detail for the different claims I make.

14 Note that it is not the agent who is "conquered" or "helplessly violated by his own desires" (Frankfurt 1971, p. 12). Rather, it is a desire that is violated by the agent's decision to $\varphi$.
} 
to do in a particular situation. In order to establish such a dilemma, a belief is needed that expresses a special means-end relation of the sort that ties together two objects of an agent's desires such that the one can only be satisfied by intentionally not satisfying the other.

Such a dilemma can be described conditionally: If I give the criminal my money, my life will be spared. If I get rid of the cargo, the ship will not wreck in the storm. If I take the drugs, I will feel better. If I wash my hands, there will be no more germs. If I do not leave the house, the CIA cannot spy on me. If I do not go camping with the kids, I avoid facing snakes (or spiders). Any of these conditional beliefs can be read as an innocent assertion not involving any sort of dilemma. But they can also describe a dilemmatic situation if the means that have to be taken to satisfy the respective desired end are costly for the agent. It can be painful to give away my savings to a criminal, ${ }^{15}$ to get rid of the precious cargo I wanted to sell, to take unhealthy drugs with severe side effects, to wash my irritated hands for 67 th time this day, to isolate myself at home, and to forbid my kids to go camping. Given that the means for an end one strongly desires are painful in this sense, then there is a conflict between the strong desire for the end and the strong desire not to do what is required as a means for it. My desire to stay alive conflicts with my desire to keep my savings (or my pride) in the hold-up situation. My desire to have germ free hands conflicts with my desire to avoid further skin irritation when I believe that the only way to have my hands clean is to wash them with disinfectants. My desire to feel better conflicts with my desire to stay away from dangerous chemical substances, if I believe that the only accessible way to feel better is to take drugs. My desire to be safe from CIA-agents spying on me conflicts with my desire to meet my friends in public places, if I believe that the best way to be safe is to avoid public places and stay at home. And my desire to avoid an encounter with a snake (or a spider) conflicts with my desire to go camping with the kids, if I believe that the best way to avoid seeing snakes (or spiders) is not to go camping.

In situations like these, the agent has to make a choice concerning which desire to go for and which desire to violate. Making a choice in such a dilemmatic situation requires to form or to recall a preference relation between the objects of the respective desires. The agent's dilemma is about whether to do the action in question or not to do it. It is a dilemma because both, doing and not doing it, lead to negative outcomes for the agent such that she has to figure out the lesser of the given two (or more) evils. This is possible because one and the same action can be considered by the agent under different descriptions. Under one description the action of taking the means is nothing but getting to the end and this is highly desirable; under another description, doing so is averse to the agent's desires. Giving the money to the criminal can be described as saving my life; but the same doing can also be described as contributing to my financial ruin. Taking drugs can be described as making me feel better; but it also can be described as jeopardising my health. Staying at home can be described

\footnotetext{
15 This can be read with different emphasis: I do not want to give my funds to the criminal or I do not want to give my funds to the criminal. Even if only small amounts of money that are not problematic for the victim are demanded by the criminal, the action of handing over the funds can be described as an action that is in conflict with one of the agent's desires, e.g. with her pride, her resenting the situation of being at the criminal's mercy etc. Thanks to an anonymous referee for pressing me on this point.
} 
as shielding myself from the CIA; but it also can be described as isolating myself and risking friendship. While the respective first description suits one of my strong desires, the second description is averse to another strong desire I have. The same is true in reverse order for the other option, that is, not doing the action in question: not giving the money to the criminal can be described as saving my funds; but it can also be described as risking my life, etc. Of course, a dilemma only arises when the agent actually has both desires and considers the action in question under at least one further description that is (unlike the first) averse to one of her strong desires. A suicidal hold-up victim may not care about being shot, and an addict who is not faced with any visible side-effects yet may not care about her health condition; these agents are not facing a dilemma of the sort that is required for acting against one's own will. An action which an agent performs as a means to a desired end is performed against her own will only if there is at least one further description of this action which the agent considers in this situation as averse to one of her strong desires.

In a positive formulation, an agent $A$ is free in her $\varphi$-ing only if no description of $\varphi$ that $A$ considers in her decision for $\varphi$-ing is in painful conflict with one of her strong desires. ${ }^{16}$ Aristotle's captain is not free in tossing his cargo overboard because he considers his doing so not only as the means to survive the storm but also under the description of driving himself to ruin which painfully violates his strong desire to be financially safe. The addict is not free in taking the drugs because she considers her doing so under the description of jeopardising her health which painfully violates her strong desire to live in good health. Albert the compulsive hand-washer is not free in washing his hands because he considers doing so under the description of causing severe pain and further skin irritation which violates his strong desire to be free from pain. The delusional believer is unfree in staying at home because she considers her doing so under the description of not meeting her friends which painfully violates her desire to enjoy their company. The person suffering from anxiety disorder is unfree in forbidding her children to go camping because she considers doing so under the description of making her children sad which is in painful conflict with her strong desire to see them happy.

Dilemmas like these can also arise for healthy, non-addicted, perfectly rational agents. Cancer-patients often do not only appreciate chemotherapy as a necessary means for their recovery but also consider it under the description of causing severe side-effects. Further, there are historically real targets of governmental conspiracy who rightly believed that they should rather not join public events. And we can imagine that a person rightly believes that the only way to get her (wounded) hands clean is to wash them. These agents' unfreedom stems from another source than the unfreedom their irrational and mentally ill analogues suffer from, but they are deprived of the same sort of freedom. All of them are unfree in what they are doing. All of them are

\footnotetext{
16 Given that $\varphi$ qualifies as an intentional doing, that is an action, this positive formulation can also be read as necessary and sufficient. But $\varphi$-ing could also be a non-intentional doing like riding a roller-coaster and then it is not sufficient that there is no description of $\varphi$-ing that the agent considers to be in conflict with one of her strong desires: the agent may fully appreciate the situation and enjoy the forces operating on her body; but since she is unable to stop doing what she is doing, she does not perform a free action because there is no action that is performed in the first place. Thanks to an anonymous referee to ask for the reason of the "only if".
} 
in a situation in which they believe that they can satisfy a strongly desired end only or best if they take certain means. ${ }^{17}$ By taking the means they violate another desire of theirs in painful awareness of this fact. In this sense, they act against their own will. For this account, the relative source of the agent's problem is irrelevant because it does not contribute to the question as to whether she performed the action against her own will. However, it seems important for another reason to what source the agent's unfreedom can be traced back: information about the origin of the agent's problem (sometimes) provides us with an explanation as to why the agent did what she did and whether the agent suffers from mental disorder or another incapacity. This may be helpful for medical treatment, but the identification of the source alone is no factor that is constitutive for an agent's unfreedom.

Note that this analysis of free and unfree action is highly case dependent; it must not be confused with an analysis that explains why drug addiction or mental disorder, by default, result in unfree behaviour. What is analysed here is freedom of action and the lack of it, but it is not an attempt to shed light on the concept of addiction or mental disorder. My approach provides conditions for freedom and unfreedom that can analyse the full range of examples that seem, at first sight, importantly different. But their difference is merely a difference in the source of an agent's unfreedom that does not require the introduction of a new sort of freedom. Compatibilist approaches to free will, free belief and free hope are superfluous when freedom of action is understood in the broad sense I suggested. What makes this approach compatibilist is not the ordinary distinction between the right and the wrong kind of determination in the sense that there is the right and the wrong kind of desires or intentions, the right and the wrong kind of beliefs, the right and the wrong kind of fear states. Acting against one's own will does not require alien motivation and irrationality though this can play a role- - a role that is by itself no constitutive element of an agent's lacking unfreedom. Rather, my account is compatibilist because determinism plays no role for the fact as to whether the agent considers her action under a description that is in painful conflict with one of her strong desires.

\section{Conclusion}

I started with a discussion of compatibilist methods as they were used in the free will debate and their application to doxastic attitudes. The main argument for doxastic freedom rests on the analogy that if there is compatibilist free will in terms of reason-responsiveness, then there is nothing in the way for an analogous freedom of belief. Epistemic reasons are, so it is argued, on a par with practical reasons; the agent's responsiveness to the respective kind of reasons is sufficient for her being in control. Cases of agents suffering from mental disorder are used in both debates as paradigm examples of agents lacking freedom of a special sort. While kleptomania and addiction are said to undermine an agent's freedom of the will, paranoia and mysophobia undermine an agent's doxastic freedom. I criticized doxastic compatibilism with regard to two points: first, reason-responsiveness and its absence are too weak to

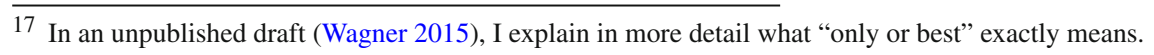


play a constitute role for either an agent's freedom or its absence. Second, I reject the method of introducing a new sort of freedom for every source of unfreedom to which the agent's problem can be traced back. These two points are connected: by modelling free will and free belief too closely on specific examples of mental disorders or incapacities, a very general criterion is needed to successfully apply it to the agent's will and her beliefs. Reason-responsiveness is such a general criterion that is applicable in the practical as well as in the epistemic realm. But because of this generality, reasonresponsiveness can be applied to far more mental attitudes than intentions and beliefs. As a consequence, doxastic compatibilists commit themselves to rather odd sorts of freedom that I demonstrated by arguing for anxiotropic compatibilism and freedom of fear when they rely on the analogy to free will in terms of reason-responsiveness. Doxastic compatibilists who reject these sorts of freedom are guilty of 'doxastic chauvinism' when judged by their own standards. I think that the best way to avoid this problem is not only to reject free fear, free hope and free anger, but also free belief and free will when based on reason-responsiveness. I argued that the crucial mistake was made when modern compatibilists rejected freedom of action too quickly as a concept that is sufficient to account for the full range of unfree agents and developed an additional sort of freedom that was tailored for the case of the unwilling addict. I sketched my own account of freedom of action and argued that all cases of unfree agency involve an agent's acting against her own will. An agent is free in her action only if no description of this action that the agent considers in her decision for doing so is in painful conflict with one of her strong desires. This is the unifying structure that explains cases of interpersonal coercion and dilemmatic situations (e.g. victim of a hold-up and Aristotle's captain), but also those cases free will and doxastic compatibilists are after: the addict, the delusional believer, the compulsive hand-washer and the phobic. Even if these agents differ with regard to the source of their unfreedom, it is the same sort of unfreedom they suffer from.

Acknowledgements For helpful comments and questions on a presentation of this paper I want to thank the audience of the workshop Doxastic Agency and Epistemic Responsibility which was hosted by Andrea Kruse and Heinrich Wansing at the University of Bochum in June 2014. I also want to thank two anonymous referees who gave detailed feedback and helpful suggestions on my paper. Further, my thanks go to Thomas Müller and my group at Konstanz University with whom I discussed a lot of the material of this paper. Last but not least, I want to thank Hans Rott for supporting me in all the non-standard views I developed with regard to the notion of freedom.

Funding The research leading to these results has received funding from the European Research Council under the European Community's Seventh Framework Programme (FP7/2007-2013)/ERC Grant agreement nr. 263227.

Open Access This article is distributed under the terms of the Creative Commons Attribution 4.0 International License (http://creativecommons.org/licenses/by/4.0/), which permits unrestricted use, distribution, and reproduction in any medium, provided you give appropriate credit to the original author(s) and the source, provide a link to the Creative Commons license, and indicate if changes were made.

\section{References}

Alston, W. P. (1988). The deontological conception of epistemic justification. Philosophical Perspectives, 2, 257-299. 
Bennett, J. (1990). Why is belief involuntary? Analysis, 50(2), 87-107.

Booth, A. R. (2014). On some recent moves in defence of doxastic compatibilism. Synthese, 191(8), 1-14.

Fischer, J. M., \& Ravizza, M. (1998). Responsibility and control: A theory of moral responsibility. Cambridge: Cambridge University Press.

Fischer, J. M., \& Ravizza, M. (2000). Précis of responsibility and control. Philosophy and Phenomenological Research, 61(2), 441-445.

Frankfurt, H. G. (1971). Freedom of the will and the concept of a person. In The importance of what we care about (pp. 11-25). Cambridge: Cambridge University Press.

Frankfurt, H. G. (1988). Coercion and moral responsibility. In The importance of what we care about (pp. 26-46). Cambridge: Cambridge University Press.

Hume, D. (1739/1740, 2006). A treatise of human nature. New York: Oxford University Press, edited and introduced by M. J. Norton and D. F. Norton.

Hume, D. (1748, 1999). In T. L. Beauchamp (Ed.), An enquiry concerning human understanding: A critical edition. Oxford: Clarendon Press.

Kavka, G. S. (1983). The toxin puzzle. Analysis, 43(1), 33-36.

LeDoux, J. (2002). The synaptical self. London: Macmillan.

Locke, J. (1689). An essay concerning human understanding. Oxford: Clarendon; edited by P. H. Nidditch: 1975 (reprinted 2011).

McHugh, C. (2011). Exercising doxastic freedom. Philosophy and Phenomenological Research, 88, 1-37.

Moore, G. E. (1912, 2005). Ethics: The nature of moral philosophy. New York: Oxford University Press, Clarendon Press.

Nottelmann, N. (2006). The analogy argument for doxastic voluntarism. Philosophical Studies, 131(3), $559-582$.

Peels, R. (2013). Against doxastic compatibilism. Philosophy and Phenomenological Research, 89(1), $679-702$.

Phelps, E. A. (2004). Human emotion and memory: Interactions of the amygdala and hippocampal complex. Current Opinion in Neurobiology, 14(2), 198-202.

Steup, M. (2008). Doxastic freedom. Synthese, 161, 375-392.

Steup, M. (2012). Belief control and intentionality. Synthese, 188(2), 145-163.

Wagner, V. (2015). Free and unfree agency: A new approach to classical compatibilism (unpublished draft).

Watson, G. (1999). Disordered appetites: Addiction, compulsion and dependence. In Agency and answerability (pp. 59-87). Oxford: Clarendon Press.

Williams, B. (1973). Deciding to believe. In Problems of the self (pp. 136-151). Cambridge: Cambridge University Press. 